Some excellent reproductions of old masters in which spectacles figure are also included, such as Giordano, the painter (1632-1705); "The Cardinal Inquisitor"' by E1 Greco (1548-1611), a "more stern looking mortal than old Torquemada." who seems from his picture to have adopted the method of keeping his glasses constantly in position by means of a thong or bootlace round the ears, a practice still to be met with among the out-patients in cases of emergency ; van Hemessen's "Surgical Operation" (1504-1575), where the operator is wearing a pair of glasses half-way down his nose ; a lovely Murillo (1656) ; Pareja (1606-1670), "The Calling of St. Mathew"; “Arias" (cir., 1684), "Caesar's Penny" ; and a picture dated 1445-1491, "The Transit of the Virgin," where a kneeling figure is using a pair of eyeglasses as a hand magnifying glass. These pictures are very well reproduced, and there is also a rather crude portrait of the author. We are grateful to Márquez, not only for his learned commentary, but also for bringing this very rare and curious work to the notice of his brother ophthalmologists throughout the world.

R.R.J.

\title{
CORRESPONDENCE
}

\section{DISLOCATION OF THE LENS}

\section{To the Editor of The British Journal of Ophthalmology}

SIR,-The articles on "Dislocation of the Lens" appearing in this month's Journal open up a subject in which I am deeply interested.

I was taught that the dislocation was a grave danger as it so frequently led to glaucoma. I inferred that the cause of the glaucoma was the mechanical obstruction caused by the lens. Whilst this may be so when the lens is in the anterior chamber, I no longer accept it as the cause when the lens is displaced either partially or completely backwards. On the contrary I believe that the cause of the glaucoma is the vitreous in the anterior chamber. I have seen a case of subluxation in which paracentesis drew off no aqueous but allowed a bead of vitreous to appear when the puncture was made to the outer side, when, however, the puncture was made up and in, aqueous came immediately with reduction of tension, and this without the patient leaving the table. Further, I believe that traumatism will produce a fluid vitreous, e.g., a patient 


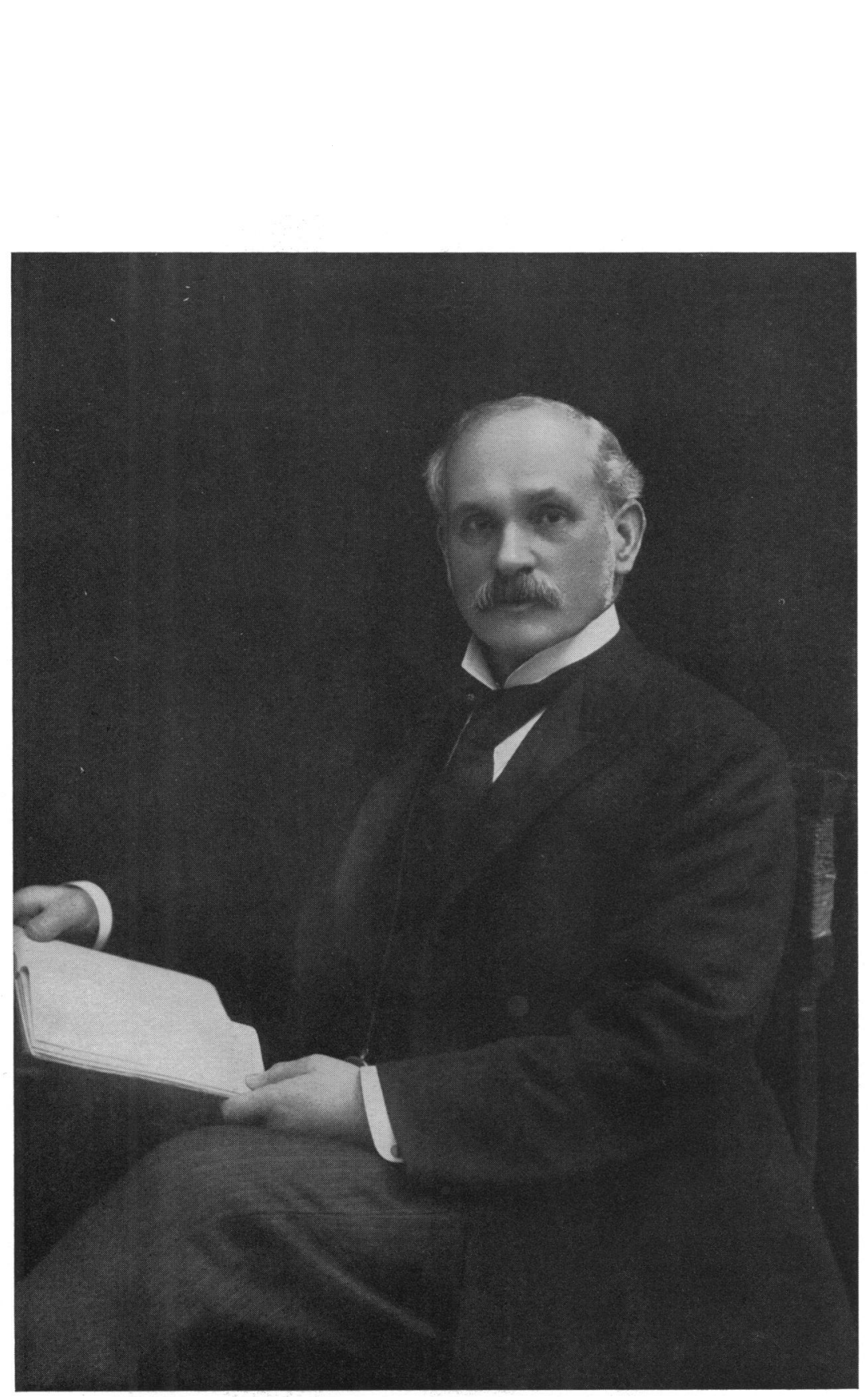

$\underline{\underline{m}}$

음

$\vec{F}$

흠

ฒ

$\overrightarrow{0}$

$\overrightarrow{\vec{\omega}}$

డ్

흥.

$\infty$

$\omega$

$\vec{\omega}$

으

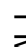

응

ก

$\overrightarrow{0}$

N

응

긍

응

용

흠

3

吾

흥.

모.

ชิ

윽

을

N

SIR JOHN TWEEDY

(1849-1924)

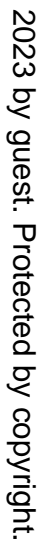


who had been struck on the eye with a large piece of iron, but without dislocation of the lens developed glaucoma. No iritis was present. Paracentesis allowed fluid vitreous to escape, as shown by the fact that the anterior chamber remained the same throughout.

These observations have led me to the conclusion that in the treatment of subluxation of the lens, some other method than extraction of the lens must be sought.

Yours faithfully,

W. A. Anderson.

24. College Gardens,

BELFAST,

7th January, 1924,

\section{OBITUARY NOTICES}

\section{SIR JOHN TWEEDY}

OPHTHALMOLOGISTS will have seen with great regret the announcement in the press of the death of SIR JOHN TWEEDY, who was the first surgeon practising purely as an ophthalmologist to obtain the highest of professional honours, the Presidency of the Royal College of Surgeons of England. This is not to say that no one interested in ophthalmology had preceded him in the Presidential chair, for Lawrence, Guthrie, Hancock, Hulke and Sir Jonathan Hutchinson were more than well known in their day as ophthalmologists, but they were all, even Hutchinson, general surgeons as well, and the fact remains that Tweedy was the first Ophthalmic Surgeon to hold this office. Tweedy was born at Stockton-on-Tees in 1849, the son of John Tweedy of that town and of Northallerton. He was educated at Elmfield College, York, and at University College, London, proceeding naturally from the College to University College Hospital for the professional part of his education. He obtained his qualification in 1872 and four years later took the F.R.C.S. A paper of his, published in the Lancet as early as 1871 on "stellation of the normal and cataractous lens" showed the ophthalmological bent of his mind. He kept in touch with his general hospital by holding for a time the post of Assistant Dermatologist, but he, very early in his career, began work at the Royal London Ophthalmic Hospital, in the service of which institution many of the best years of his life were spent; he was appointed Assistant Surgeon to the Hospital in 1879. At about the same time he obtained the appointment of Ophthalmic Surgeon to the Great Northern Hospital, and in 1881, that of Assistant Ophthalmic Surgeon to 